\title{
Total Synthesis of (-)- and ent-(+)-Vindoline
}

\author{
Younggi Choi, Hayato Ishikawa, Juraj Velcicky, Gregory I. Elliott, Michael M. Miller, and Dale \\ L. Boger \\ Department of Chemistry and Skaggs Institute for Chemical Biology, The Scripps Research \\ Institute, 10550 North Torrey Pines Road, La Jolla, California 92037
}

\begin{abstract}
Two exceptionally concise total syntheses of (-)- and ent-(+)-vindoline are detailed enlisting a diastereoselective tandem $[4+2] /[3+2]$ cycloaddition of a 1,3,4-oxadiazole. The unique reaction cascade assembles the fully functionalized pentacyclic ring system of vindoline in a single step that forms four $\mathrm{C}-\mathrm{C}$ bonds and three rings while introducing all the requisite functionality and setting all six stereocenters within the central ring including three contiguous and four total quaternary centers.
\end{abstract}

Vinblastine (1) and vincristine (2) constitute the most widely recognized members of the class of bisindole alkaloids as a result of their clinical use as antineoplastic drugs (Figure 1a). ${ }^{1}$

Originally isolated in trace quantities from Cantharanthus roseus (L.) G. Don, ${ }^{2}$ their biological properties were among the first to be shown to arise from inhibition of microtubule formation and mitosis that today is still regarded as one of the more successful drug targets for the treatment of cancer. ${ }^{3}$ In addition to being among the first natural products whose structures were determined by X-ray crystallography of a derivative, they were among the first for which $\mathrm{X}$-ray was used to establish their absolute configuration. ${ }^{4}$ Vindoline $(\mathbf{3})^{4,5}$ a major alkaloid of Cantharanthus roseus, constitutes the most complex half of vinblastine and serves as both a biosynthetic ${ }^{2}$ and synthetic ${ }^{6}$ precursor to the natural product. ${ }^{7}$

Herein, we detail two first generation total syntheses of vindoline that complement past efforts $7,8,9$ enlisting a unique tandem intramolecular $[4+2] /[3+2]$ cycloaddition cascade of 1,3,4-oxadiazoles. ${ }^{10}$ In these studies, key issues regarding the scope and stereochemical features of the cycloaddition cascade were defined and its potential for use in the construction of the vindoline structure established. Thus, two concise routes to $\mathbf{3}$ are detailed enlisting the tandem cycloaddition reactions of either 1,3,4-oxadiazole $\mathbf{4 a}$ or $\mathbf{4 b}$, each of which assembles the fully functionalized pentacyclic ring system of $\mathbf{3}$ with formation of four $\mathrm{C}-\mathrm{C}$ bonds and three rings in a single step setting all six stereocenters within the central ring of vindoline including three contiguous and four total quaternary centers (Figure 1b).

The preparation of the 1,3,4-oxadiazole precursors 4 is summarized in Scheme 1. Treatment of $\mathrm{N}$-methyl-6-methoxytryptamine (6) ${ }^{11}$ with phenylcarbonate followed by hydrazine provided 7 (64\%) which was coupled with methyl oxalate (EDCI, DMAP, $\mathrm{CH}_{2} \mathrm{Cl}_{2}, 23{ }^{\circ} \mathrm{C}$, $61 \%$ ) to provide 9 (see supporting information). Alternatively, 6 was first treated with carbonyldiimidazole (CDI) to form $\mathbf{8}(90 \%)$ and subsequently treated with methyl oxalylhydrazide $^{12}$ to furnish 9 (79\%). Cyclization via dehydration of $\mathbf{9}$ (1.0 equiv of TsCl, 2.5 equiv of $\mathrm{Et}_{3} \mathrm{~N}, \mathrm{CH}_{2} \mathrm{Cl}_{2}, 67 \%$ ) provided 10 which was coupled with isomerically pure $(Z)$ - or (E)-11 to provide $\mathbf{4 a}(96 \%)$ and $\mathbf{4 b}(88 \%)$. 
Both $\mathbf{4 a}$ and $\mathbf{4 b}$ undergo the tandem $[4+2] /[3+2]$ cycloaddition cascade to give the pentacyclic products $\mathbf{5 a}$ and $\mathbf{5 b}$, respectively, as single diastereomers (Figure $1 \mathbf{b}$ ). The reaction leading to $\mathbf{5}$ is initiated by an intramolecular inverse electron demand Diels-Alder cycloaddition of the 1,3,4-oxadiazole with the tethered enol ether. Loss of $\mathrm{N}_{2}$ from the initial cycloadduct $\mathbf{A}$ provides the carbonyl ylide $\mathbf{B}$ (eq. 1), which undergoes a subsequent established ${ }^{13}$ 1,3-dipolar cycloaddition with the tethered indole. Importantly, the diene and dienophile substituents complement and reinforce the [4+2] cycloaddition regioselectivity dictated by the linking tether, the intermediate 1,3-dipole is stabilized by the complementary substitution at the dipole termini, and the

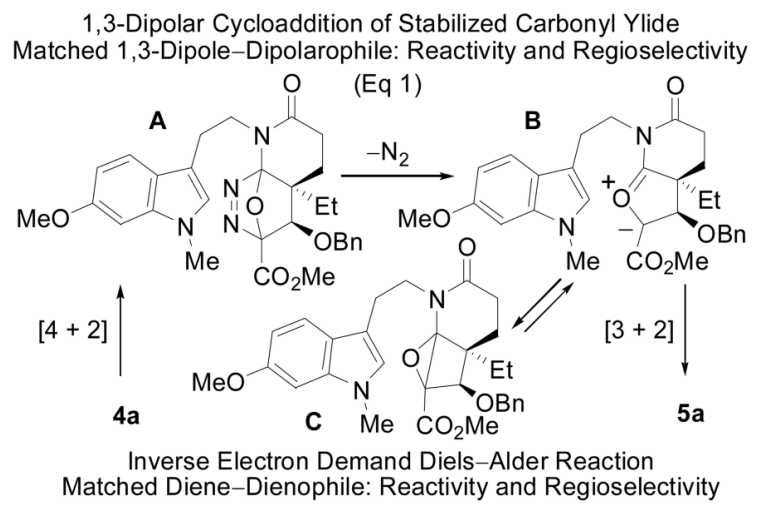

tethered 1,3-dipolarophile (indole) complements the [3+2] cycloaddition regioselectivity that is dictated by the linker tether. The relative stereochemistry in each cycloadduct is controlled by a combination of (1) the dienophile geometry and (2) an exclusive endo indole [3+2] cycloaddition ${ }^{13}$ sterically directed to the $\alpha$-face opposite the newly formed fused lactam. This endo diastereoselection for the 1,3-dipolar cycloaddition may be attributed to a conformational (strain) preference dictated by the dipolarophile tether since it mirrors the relative energy of the four possible products. ${ }^{10}$ The stereochemical assignments for $\mathbf{4 a}$ and $\mathbf{4 b}$ were based initially on their ${ }^{1} \mathrm{H}$ NMR spectroscopic properties and unambiguously established by X-ray. 14 Thus, the cycloaddition cascade of either $4 \mathbf{a}$ and $4 \mathbf{b}$ provides complete control of the intrinsic stereochemistry found in the pentacyclic skeleton of the Aspidosperma alkaloids, establishing all six stereocenters about the central six-membered ring and was designed to introduce essentially all the functionality found in $\mathbf{3}$. The distinction in the two cycloaddition cascades being that $4 \mathbf{a}$ permits the direct introduction of the naturally occurring $\mathrm{C} 4 \mathrm{OAc} \beta$ stereochemistry, whereas $\mathbf{4 b}$ provides the $\mathrm{C} 4$ epimer requiring a subsequent inversion of configuration at this center. Although substrate $\mathbf{4 a}$ directly provides the preferred cycloadduct $\mathbf{5 a}$ for the use in the synthesis of $\mathbf{3}$, it proved to be more difficult to implement. The cyclization of 4a occurs in excellent yield when warmed in triisopropylbenzene (TIPB) for $60 \mathrm{~h}$ affording $\mathbf{5 a}$ as a single diastereomer (Figure 1b). Initial attempts to cyclize 4a provided $\mathbf{5 a}$ in low yield $(<30 \%$ at $>5 \mathrm{mM})$ which is in contrast to the cyclization of the $\mathbf{4 b}$ which provides the $\mathrm{C} 4$ diastereomer (84-99\%). However, simple dilution of the reaction mixture led to improved yields (up to 53\%). A study of this concentration effect is illustrated in Table 1 for both 4a and $\mathbf{4 b}$, where a rather dramatic relationship between concentration and yield was found, especially for $\mathbf{4 a}$, suggesting that a bimolecular 1,3-dipolar cycloaddition reaction of $\mathbf{4}$ may compete with the intramolecular cycloaddition cascade at the higher reaction concentrations. More significantly, we observed that the [4+2] cycloaddition is now the fast step in the reaction cascade and that the subsequent [3+2] cycloaddition is the slow step for $\mathbf{4 a}$, a reversal of what is observed with $\mathbf{4 b}$ and other typical substrates. ${ }^{10}$ The net consequence is that longer reaction times and/or more vigorous reaction conditions, in conjunction with the use of a dilute reaction concentration, led to substantial improvements in the conversion of $\mathbf{4 a}$. The origin of the distinctions in the slow step of the cycloaddition cascade $4 \mathbf{a}$ versus $\mathbf{4 b}$ is not yet clear. The 1,3- 
dipolar cycloaddition transition state for $\mathbf{4 b}$ embodies the more serious steric interactions disfavoring the indole endo approach on the $\alpha$-face of the 1,3-dipole (Figure 1b), yet it progresses with a greater facility than that of $\mathbf{4 a}$. It appears that the transition state for the 1,3dipolar cycloaddition derived from $4 \mathbf{a}$ suffers a destabilizing electrostatic interaction of its central oxygen with the (Z)-OBn substituent (Figure $1 b$ ) that decelerates the reaction and/or that the $(E)-\mathrm{OBn}$ substituent of $\mathbf{4 b}$ stabilizes its transition state (transition state anomeric effect). However, it is also possible that the preferred stereochemistry of the corresponding cyclobutene epoxide $\mathbf{C}$ or their relative stability, a potential intermediate and reversible source of the 1,3dipole, may dictate the relative ease of the 1,3-dipolar cycloaddition and studies to probe such questions are in progress.

Although unanticipated, we found that the enantiomers of $\mathbf{5 a}$ could be easily separated on a semipreparative Chiralcel OD column $(30 \% i-\mathrm{PrOH}$-hexanes, $2 \times 25 \mathrm{~cm})$ with a remarkable efficiency $\left(\alpha=1.70, t_{R}=15.1\right.$ and $\left.25.6 \mathrm{~min}, 10 \mathrm{~mL} / \mathrm{min}\right)$ providing access to either of enantiomer on a preparatively useful scale ( $40-100 \mathrm{mg} /$ injection). $\alpha$-Hydroxylation of $\mathbf{5 a}$ was achieved best by treatment of the lactam enolate with TMSO-OTMS and was followed by a direct quench with TIPSOTf providing 12 (56-64\%), Scheme 2 (natural enantiomer shown). The stereochemistry of the $\alpha$-hydroxylation was clear from the ${ }^{1} \mathrm{H}$ NMR of $12(\mathrm{C} 7-\mathrm{H}, J=5.5$, $11.7 \mathrm{~Hz}$ ) and unambiguously determined by $\mathrm{X}$-ray of the corresponding $p$-bromobenzoate.

${ }^{14}$ Conversion of 12 to thioamide $\mathbf{1 3}(70 \%)$ with Lawesson's reagent, reductive desulfurization with $\mathrm{Ra}-\mathrm{Ni}$ conducted under conditions $\left(15 \mathrm{~h}, 23^{\circ} \mathrm{C}\right)$ that also served to cleave the benzyl ether provided 14 (91\%), and subsequent acetylation of the resulting secondary alcohol afforded $15(97 \%)$. Diastereoselective reductive cleavage of the oxido bridge upon catalytic hydrogenation ( $45 \mathrm{psi} \mathrm{H}_{2}, \mathrm{PtO}_{2}$, EtOAc) with reduction of the intermediate imminium ion from the $\alpha$-face provided 16 (98\%) analogous to observations first made by Padwa, ${ }^{13}$ silyl ether cleavage $\left(\mathrm{Bu}_{4} \mathrm{NF}, 89 \%\right)$, and subsequent secondary alcohol activation and elimination of $\mathbf{1 7}$ $\left(\mathrm{Ph}_{3} \mathrm{P}, \mathrm{DEAD}, \mathrm{THF}, 23{ }^{\circ} \mathrm{C}\right)$ provided either $(-)$ - or ent-(+)-vindoline $(75 \%)$ identical in all respects with authentic material. The final conversion of $\mathbf{1 7}$ to $\mathbf{3}$ enlisting a Mitsunobu activation of the secondary alcohol for elimination may proceed via an intermediate aziridinium cation and relies on the reagent-derived base $\left(\mathrm{EtO}_{2} \mathrm{CNHN}^{-}-\mathrm{CO}_{2} \mathrm{Et}\right)$ to promote the regioselective elimination. This protocol proved much more effective and reproducible than alternative procedures that enlist reagents (e.g., $\left.\mathrm{Ph}_{3} \mathrm{P}-\mathrm{CCl}_{4}\right){ }^{15}$ that generate reactive nucleophiles (e.g., $\mathrm{Cl}^{-}$) that can complete with the elimination reaction.

A second total synthesis of vindoline was accomplished utilizing cycloadduct $\mathbf{5 b}$ and was conducted while efforts to secure 5a were underway (Scheme 3). The advantage being that the key cycloaddition cascade proceeds with greater facility under milder conditions and in higher conversions (>95\%), albeit in a route requiring inversion of the C4 stereochemistry. Thus, $\alpha-$ hydroxylation of $\mathbf{5 b}$ (LDA, TMSO-OTMS) followed by in situ treatment with TIPSOTf provided 18 in superb yield (75\%). The stereochemistry of the intermediate alcohol, also obtained by a less effective reaction of the lactam enolate with Davis' reagent (40-50\%), was established by ${ }^{1} \mathrm{H}$ NMR $(\mathrm{C} 7-\mathrm{H}, J=5.5,12.1 \mathrm{~Hz})$ and confirmed by X-ray. ${ }^{14} \mathrm{C} 4$-Alcohol deprotection $\left(\mathrm{H}_{2}, \mathrm{Pd} / \mathrm{C}, 90 \%\right)$ and oxidation of $\mathbf{1 9}$ with TPAP/NMO provided $\mathbf{2 0}(81 \%)$. Thiolactam formation (Lawesson's reagent, toluene, 81\%) and Ra-Ni desulfurization of 21 (25 $\left.{ }^{\circ} \mathrm{C}, 78 \%\right)$ preceded diastereoselective oxido bridge cleavage of $\mathbf{2 2}\left(\mathrm{H}_{2}, \mathrm{PtO}_{2}, \mathrm{MeOH}, \mathrm{H}^{+}\right){ }^{13}$ to furnish $23(82 \%)$. TIPS ether cleavage $\left(\mathrm{Bu}_{4} \mathrm{NF}, 98 \%\right)$ and treatment of 24 with $\mathrm{Ph}_{3} \mathrm{P}-$ $\mathrm{CCl}_{4}{ }^{15}$ led to activation and elimination of the $\mathrm{C} 7$ alcohol to provide 25 (62\%). Following the protocol of Büchi, ${ }^{8}$ diastereoselective $\mathrm{C} 4$ carbonyl reduction of $\mathbf{2 5}$ (Redal- $\left.\mathrm{H}, \mathrm{AlCl}_{3}\right)$ and subsequent acetylation $\left(\mathrm{Ac}_{2} \mathrm{O}, 83 \%\right)$ of deacetylvindoline (26) furnished vindoline (3).

\section{Supporting Information Available}

Refer to Web version on PubMed Central for supplementary material. 


\section{Acknowledgements}

We gratefully acknowledge the financial support of the National Institute of Health (CA42056) and the Skaggs Institute for Chemical Biology and wish to thank Y. Li for providing material at an intermediate stage of the studies.

\section{References}

1. Neuss, N.; Neuss, MN. The Alkaloids. Brossi, A.; Suffness, M., editors. 37. Academic; San Diego: 1990. p. 229

2. a Noble RL, Beer CT, Cutts JH. Ann N Y Acad Sci 1958;76:882. [PubMed: 13627916] b Noble RL. Lloydia 1964;27:280. c Svoboda GH, Nuess N, Gorman M. J Am Pharm Assoc Sci Ed 1959;48:659.

3. a Owellen RI, Hartke CA, Dickerson RM, Haines FO. Cancer Res 1976;36:1499. [PubMed: 1260766] Pearce, HL. The Alkaloids. Brossi, A.; Suffness, M., editors. 37. Academic; San Diego: 1990. p. 145

4. Moncrief JW, Lipscomb WN. J Am Chem Soc 1965;87:4963. [PubMed: 5844471]

5. Gorman M, Neuss N, Biemann K. J Am Chem Soc 1962;84:1058.

6. a Mangeney P, Andriamialisoa RZ, Langlois N, Langlois Y, Potier P. J Am Chem Soc 1979;101:2243. b Kutney JP, Choi LSL, Nakano J, Tsukamoto H, McHugh M, Boulet CA. Heterocycles 1988;27:1845. c Kuehne ME, Matson PA, Bornmann WG. J Org Chem 1991;56:513. d Magnus P, Mendoza JS, Stamford A, Ladlow M, Willis P. J Am Chem Soc 1992;114:10232. e Yokoshima S, Ueda T, Kobayashi S, Sato A, Kuboyama T, Tokuyama H, Fukuyama T. J Am Chem Soc 2002;124:2137. [PubMed: 11878966]Kuboyama T, Yokoshima S, Tokuyama H, Fukuyama T. Proc Natl Acad Sci USA 2004;101:11966. [PubMed: 15141084]

7. Review: KuehneMEMarkoIThe AlkaloidsBrossiASuffnessMAcademicSan Diego19903777

8. Racemic total syntheses: a Ando M, Büchi G, Ohnuma T. J Am Chem Soc 1975;97:6880. b Kutney JP, Bunzli-Trepp U, Chan KK, De Souza JP, Fujise Y, Honda T, Katsube J, Klein FK, Leutwiler A, Morehead S, Rohr M, Worth BR. J Am Chem Soc 1978;100:4220. c Andriamialisoa RZ, Langlois N, Langlois Y. J Org Chem 1985;50:961. Formal racemic total syntheses: d Ban Y, Sekine Y, Oishi T. Tetrahedron Lett 1978;2:151. e Takano S, Shishido K, Sato M, Yuta K, Ogasawara K. J Chem Soc Chem Commun 1978:943.Takano S, Shishido K, Matsuzaka J, Sato M, Ogasawara K. Heterocycles 1979;13:307. f Danieli B, Lesma G, Palmisano G, Riva R. J Chem Soc Chem Commun 1984:909.Danieli B, Lesma G, Palmisano G, Riva R. J Chem Soc Perkin Trans 1 1987:155. g Zhou S, Bommeziijn S, Murphy JA. Org Lett 2002;4:443. [PubMed: 11820900]

9. Enantioselective total syntheses: a Feldman PL, Rapoport H. J Am Chem Soc 1987;109:1603. b Kuehne ME, Podhorez DE, Mulamba T, Bornmann WG. J Org Chem 1987;52:347. c Kobayashi S, Ueda T, Fukuyama T. Synlett 2000:883. Formal enantioselective total syntheses: Cardwell K, Hewitt B, Ladlow M, Magnus P. J Am Chem Soc 1988;110:242.

10. a Wilkie GD, Elliott GI, Blagg BSJ, Wolkenberg S, Soenen DR, Miller MM, Pollack S, Boger DL. J Am Chem Soc 2002;124:11292. [PubMed: 12236743] b Yuan ZQ, Ishikawa H, Boger DL. Org Lett 2005;7:741. [PubMed: 15704939]

11. Takano S, Shishido K, Matsuzaka J, Sato M, Ogasawara K. Heterocycles 1979;13:307.An improved preparation is detailed in the supporting information.

12. Christl M, Lanzendoerfer U, Groetsch MM, Ditterich E, Hergmann J. Chem Ber 1990;123:2031.

13. Padwa A, Price AT. J Org Chem 1998;63:556. [PubMed: 11672045]1995;60:6258. Interestingly, intermolecular $[3+2]$ variants proceed with indole exo cycloaddition directed to an analogous $\alpha$-face, see: Muthusamy S, Gunanathan C, Babu SA. Tetrahedron Lett 2001;42:523.

14. X-ray crystal structures of $\mathbf{5 a}$ (CCDC 253429), 5b (CCDC 253430), the C7 p-bromobenzoate of 12 (CCDC 255976), and the C7 free alcohol of 18 (CCDC 253428) have been deposited with the Cambridge Crystallographic Data Centre.

15. Kuehne ME, Okuniewicz FJ, Kirkemo CL, Bohnert JC. J Org Chem 1982;47:1335. 


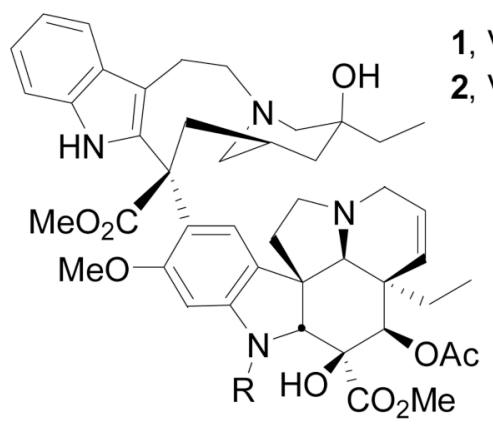

1, Vinblastine $\mathrm{R}=\mathrm{CH}_{3}$

2, Vincristine $\mathrm{R}=\mathrm{CHO}$
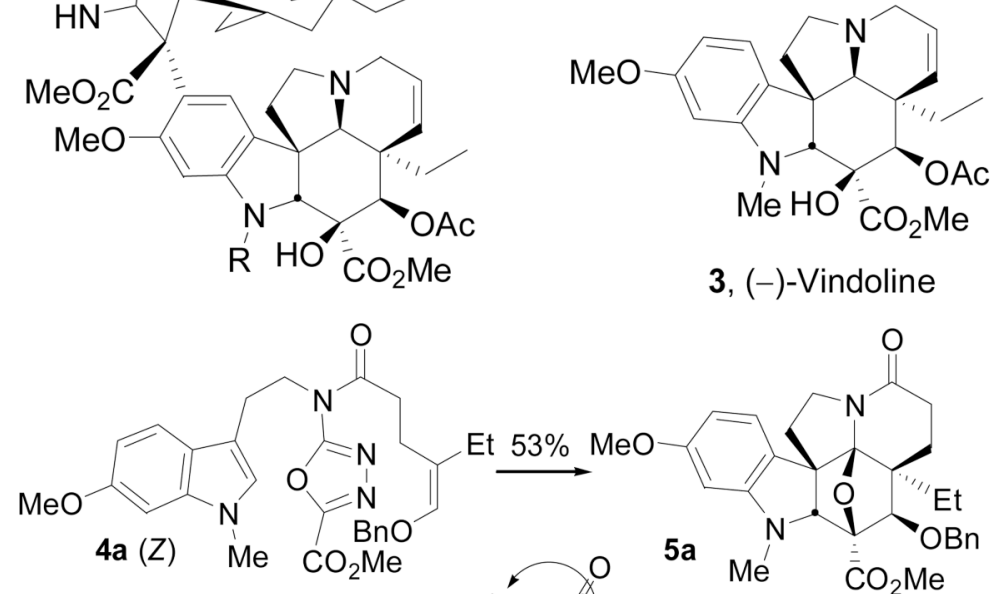

3, (-)-Vindoline
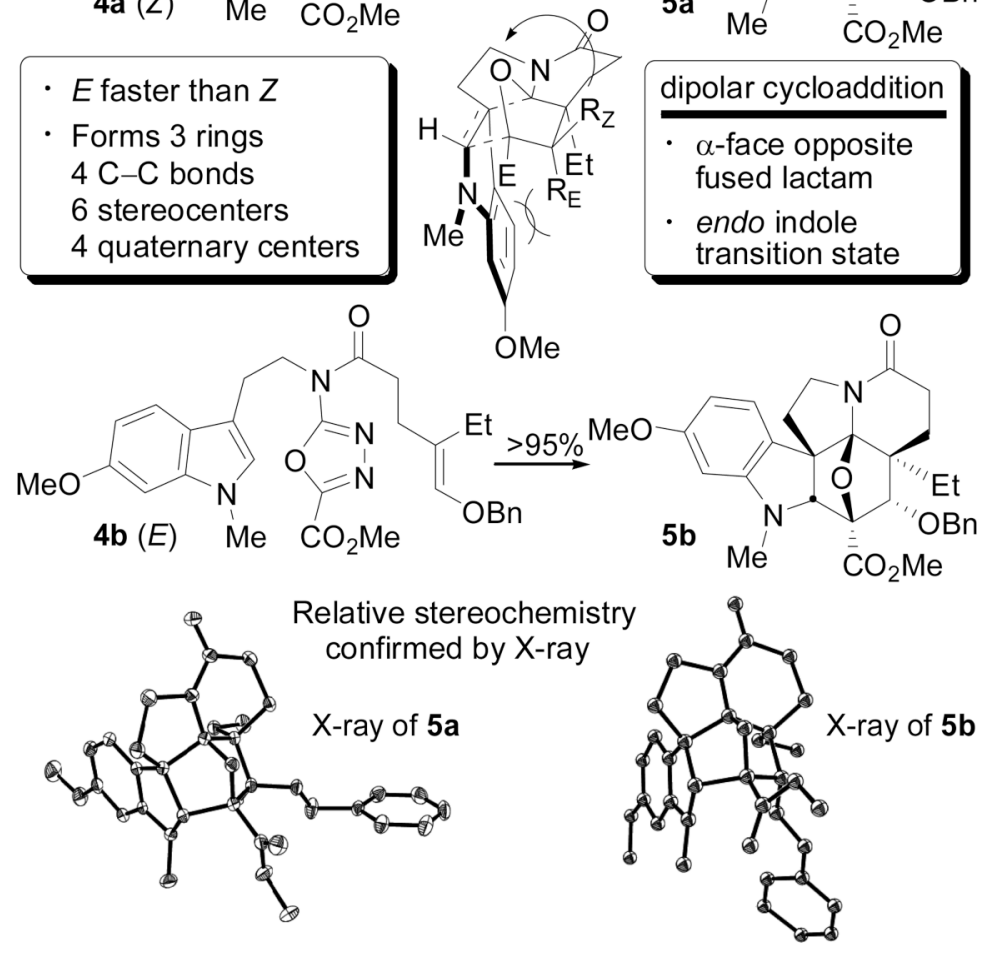

Figure 1.

Figure 1a. Natural product structures.

Figure $1 \boldsymbol{b}$. Key cycloaddition cascade. 


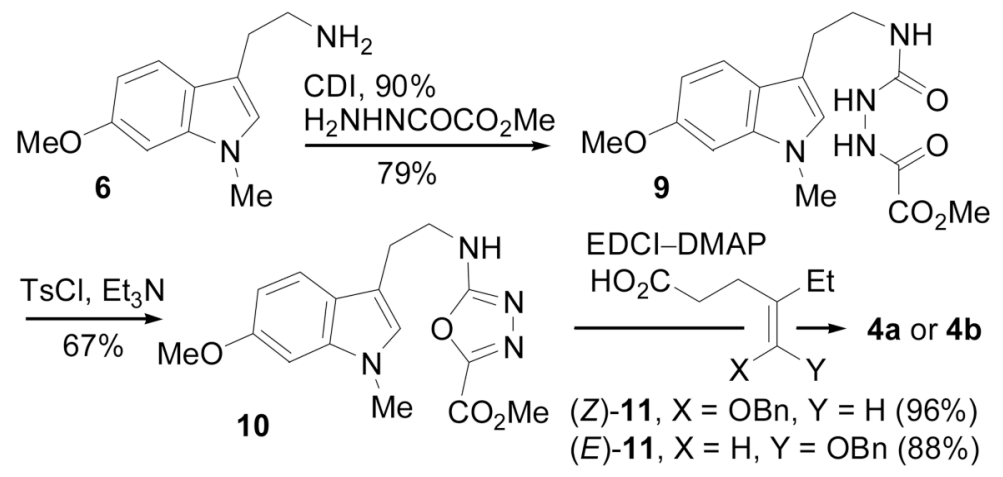

Scheme 1. 


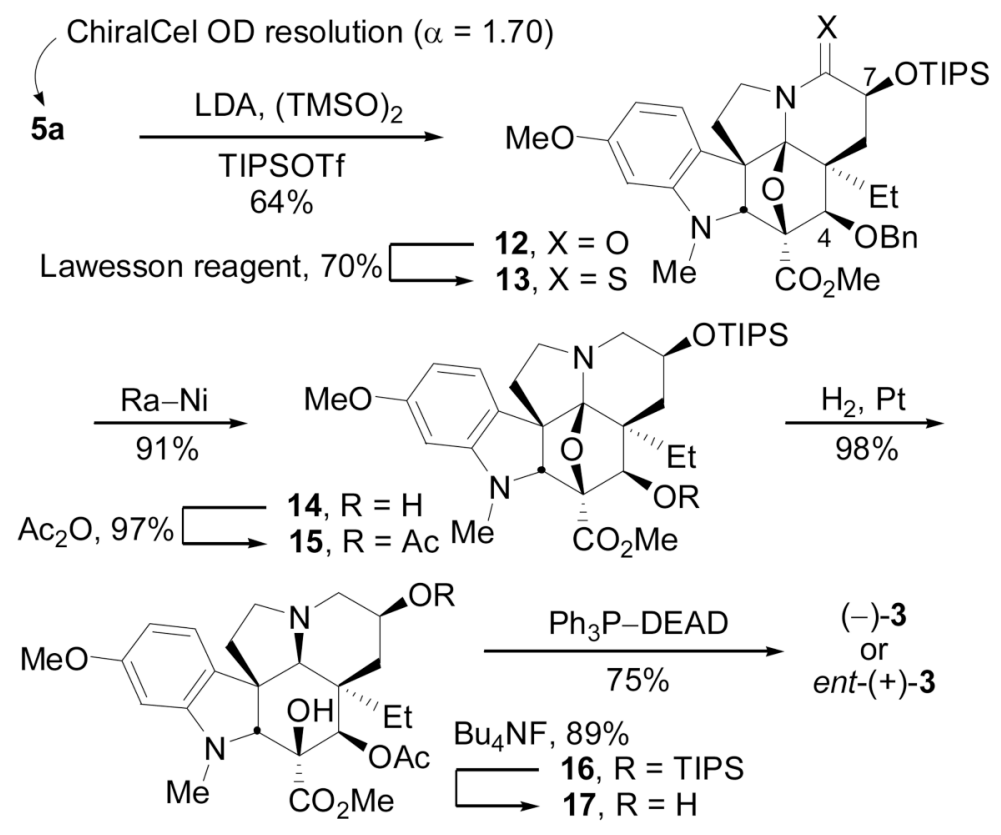

Scheme 2. 

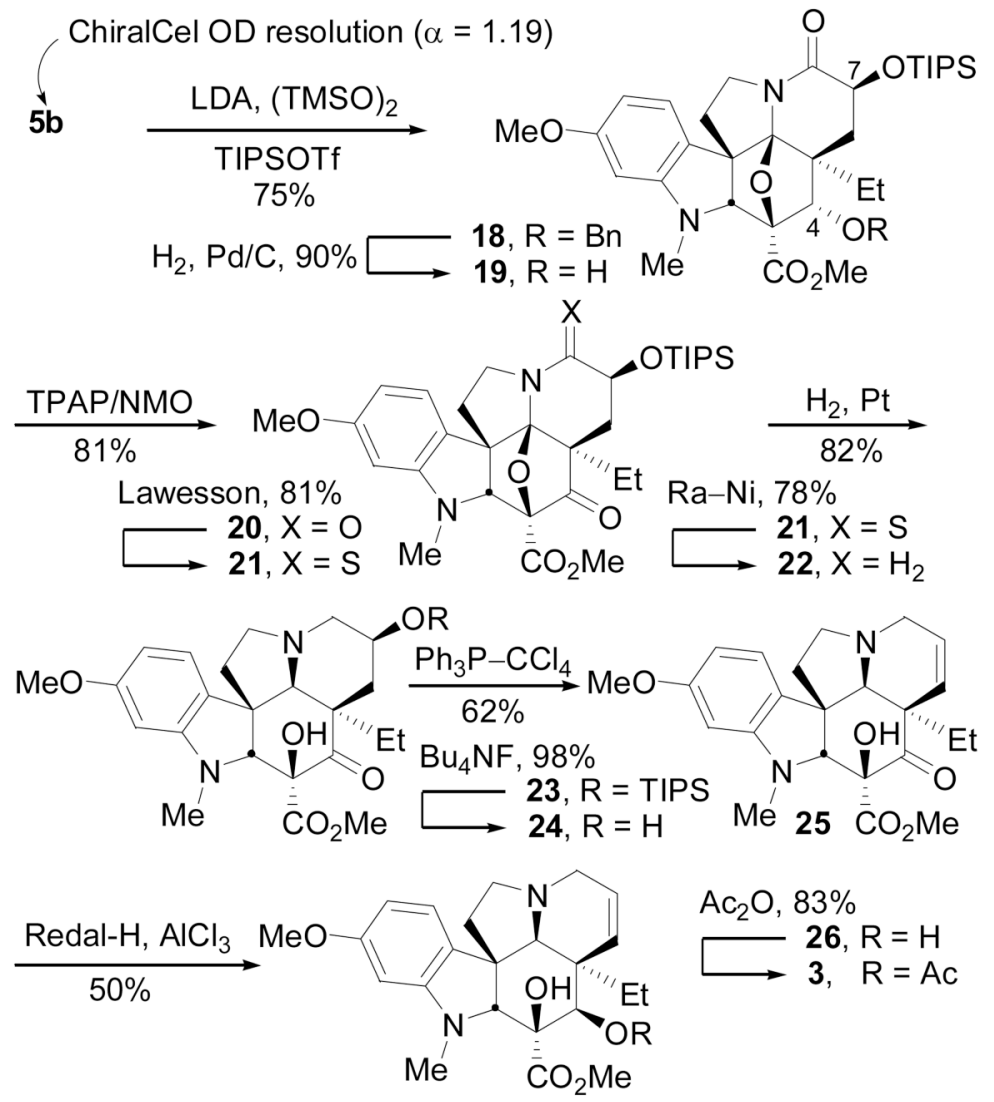

Scheme 3. 
Table 1

Cycloaddition Concentration Dependence

\begin{tabular}{lrr}
\hline compound & conc. (mM) & \% yield 5a or 5b \\
\hline $\mathbf{4 a}^{a}$ & $5 \mathrm{mM}$ & $27-34 \%$ \\
$\mathbf{4} \mathbf{a}^{a}$ & $1 \mathrm{mM}$ & $43 \%$ \\
$\mathbf{4} \mathbf{a}^{a}$ & $0.1 \mathrm{mM}$ & $50 \%$ \\
$\mathbf{4} \mathbf{a}^{a}$ & $0.05 \mathrm{mM}$ & $53 \%$ \\
$\mathbf{4} \mathbf{b}^{b}$ & $100 \mathrm{mM}$ & $38 \%$ \\
$\mathbf{4} \mathbf{b}^{b}$ & $50 \mathrm{mM}$ & $58 \%$ \\
$\mathbf{4} \mathbf{b}^{b}$ & $10 \mathrm{mM}$ & $86 \%$ \\
$\mathbf{4} \mathbf{b}^{b}$ & $5 \mathrm{mM}$ & $90 \%$ \\
$\mathbf{4} \mathbf{b}^{b}$ & $1 \mathrm{mM}$ & $99 \%$ \\
\hline
\end{tabular}

${ }^{a}$ Condition: $230{ }^{\circ} \mathrm{C}$, TIPB, $90 \mathrm{~h}$.

${ }^{b}$ Condition: $230{ }^{\circ} \mathrm{C}$, TIPB, $20 \mathrm{~h}$. 